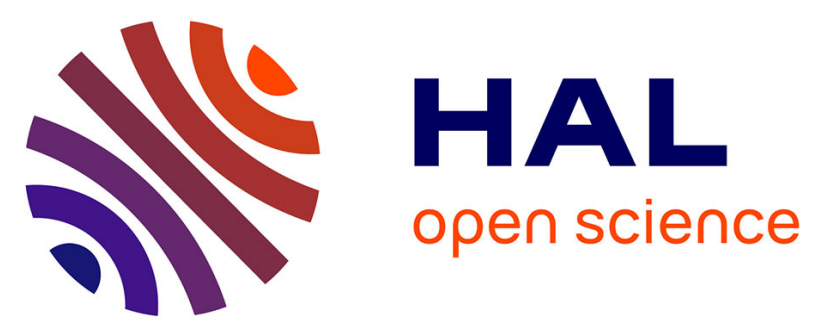

\title{
AIDSIMPACT SPECIAL ISSUE The societal burden of HIV/AIDS in Northern Italy: an analysis of costs and quality of life
}

Gijs Antoon Adriaan Hubben, David Bishai, Petros Pechlivanoglou, Anna Maria Cattelan, Roberta Grisetti, Chiara Facchin, F Compostella, Jasper Bos, Maarten Postma, A Tramarin

\section{To cite this version:}

Gijs Antoon Adriaan Hubben, David Bishai, Petros Pechlivanoglou, Anna Maria Cattelan, Roberta Grisetti, et al.. AIDSIMPACT SPECIAL ISSUE The societal burden of HIV/AIDS in Northern Italy: an analysis of costs and quality of life. AIDS Care, 2008, 20 (04), pp.449-455. 10.1080/09540120701867107 . hal-00513451

\section{HAL Id: hal-00513451 \\ https://hal.science/hal-00513451}

Submitted on 1 Sep 2010

HAL is a multi-disciplinary open access archive for the deposit and dissemination of scientific research documents, whether they are published or not. The documents may come from teaching and research institutions in France or abroad, or from public or private research centers.
L'archive ouverte pluridisciplinaire HAL, est destinée au dépôt et à la diffusion de documents scientifiques de niveau recherche, publiés ou non, émanant des établissements d'enseignement et de recherche français ou étrangers, des laboratoires publics ou privés. 

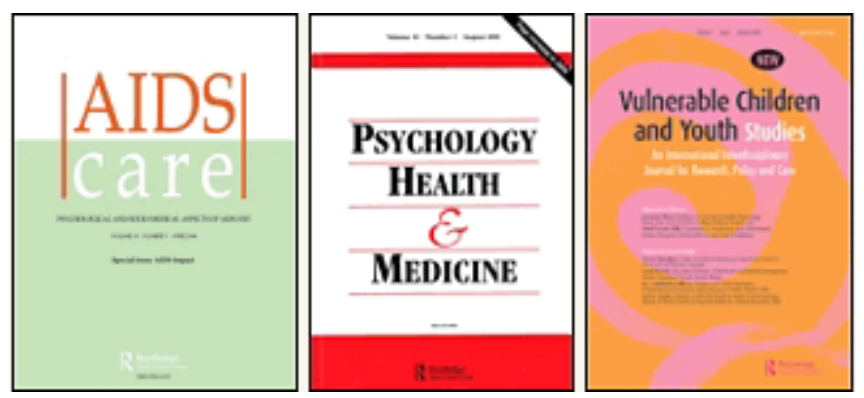

AIDSIMPACT SPECIAL ISSUE The societal burden of HIV/AIDS in Northern Italy: an analysis of costs and quality of life

\begin{tabular}{|r|l|}
\hline Journal: & $\begin{array}{l}\text { AIDS Care - Psychology, Health \& Medicine - Vulnerable Children } \\
\text { and Youth Studies }\end{array}$ \\
\hline Manuscript ID: & AC-2007-08-0422.R1 \\
\hline Journal Selection: & AIDS Care \\
\hline Keywords: & hiv aids care, direct costs, indirect costs, quality of life, italy \\
\hline \multicolumn{2}{|r}{} \\
\hline
\end{tabular}

\section{scholaroNE" \\ Manuscript Central}




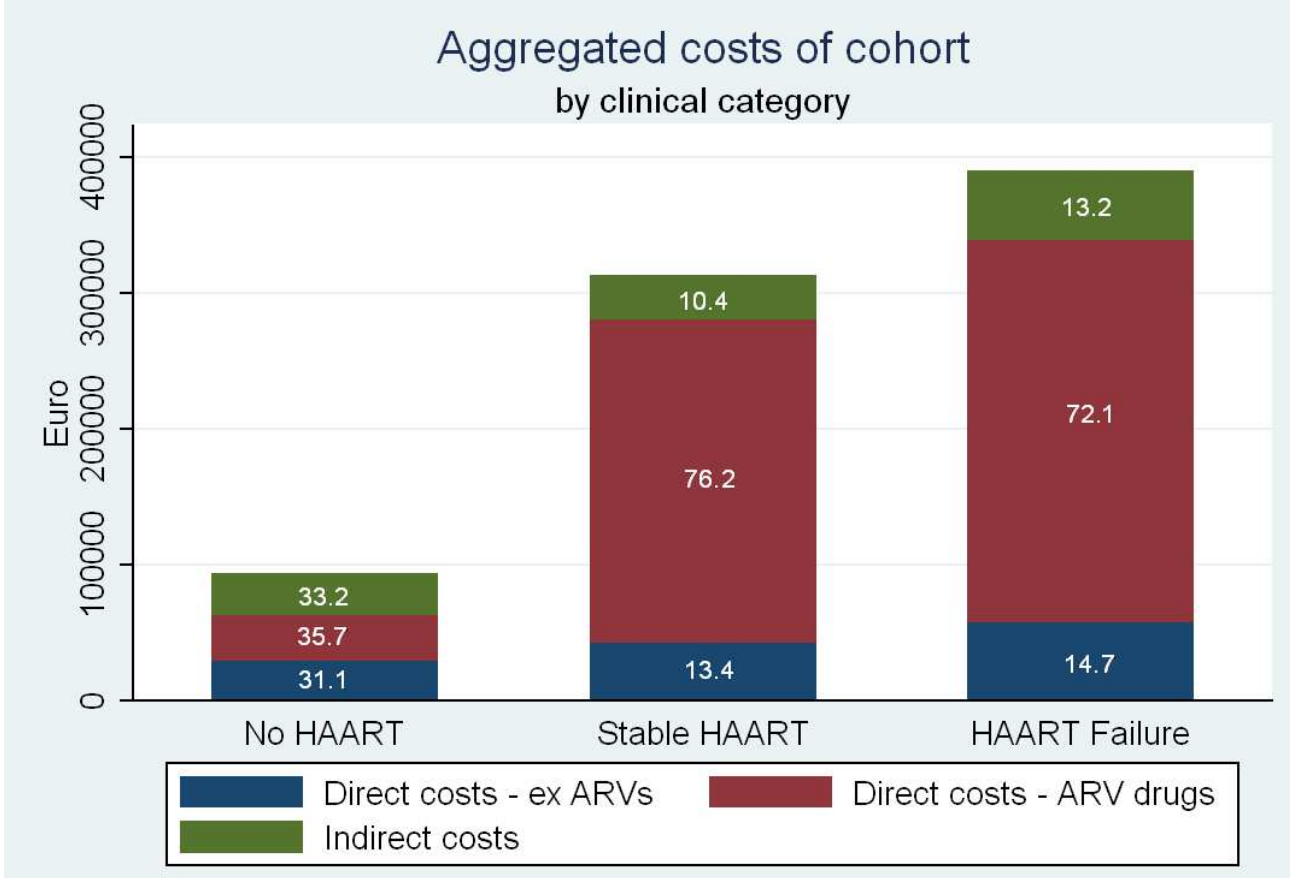

$381 \times 268 \mathrm{~mm}(72 \times 72 \mathrm{DPI})$ 


\title{
The societal burden of HIV/AIDS in Northern Italy: an analysis of costs and quality of life
}

\begin{abstract}
This study aims to measure the direct and indirect costs of HIV/AIDS care and quality of life of HIV infected patients in Northern Italy. We conducted a prospective cohort study over 12 months, enrolling a sample of 121 patients with HIV infection from 2 cities in Northern Italy. Patients were surveyed at baseline and were followed-up at 6 and 12 months. To assess the relationship between costs and stage of disease, patients were categorized into three groups at baseline: 'No HAART' (asymptomatic and never before on HAART), 'Stable HAART' (HAART with mild HIV infection and no prior opportunistic infections) and 'HAART failure' (primary HAART regimen was altered because of severe side effects or immunological failure). Direct medical costs were based on utilization of (day) hospital admissions, diagnostic procedures, laboratory tests, clinic visits, consultations and antiretroviral drug use. Indirect costs included production losses due to absence from work, reduced productivity at work and reduced unpaid labour participation. Quality of life was assessed by visual analogue scale. Parametric regression was used to estimate the expected value and the standard deviation of annual costs per patient. The expected value of total annual costs was $€ 1,818$ and $€ 9,820$ and $€ 12,332$, for groups 'No HAART', 'Stable HAART', and 'HAART failure' respectively. We estimated annual expected earnings as €14,994 and $€ 10,811$ and $€ 9,820$ for the same respective groups. The expected value of quality of life on a scale of $0-1$ in these same patient groups was $0.80,0.78$ and 0.64 . We conclude that indirect costs contribute substantially to total costs and are comparable in magnitude to the direct costs excluding antiretroviral drugs. The costs of inpatient care in our cohort were almost negligible compared to total costs. Despite being in treatment, many patients were still gainfully employed and generated substantial expected annual earnings.
\end{abstract}




\section{Introduction}

The use of highly active antiretroviral therapy (HAART) has been associated with declines in mortality, opportunistic infections and hospitalizations (Mocroft et al., 1998; Mocroft et al., 2004; Palella, Jr. et al., 1998). The introduction of HAART has resulted in significant higher costs for therapeutics, while reductions have been observed in healthcare resource use due to the prevention of opportunistic infections (Gebo et al., 1999). Since the mid-nineties, this has

resulted in a shift from inpatient towards outpatient care, which has been reported by several

Deleted: to authors (Garattini et al., 2001; Tramarin et al., 2004). However, a recent review by Levy et al. on the direct costs of HIV/AIDS care revealed that there are few recent studies that provide adequate information on the costs of HIV/AIDS care (Levy et al., 2006). Even fewer studies evaluate the indirect costs of HIV/AIDS care, although indirect costs should formally be included when evaluating healthcare interventions from the societal perspective (Drummond MF et al., 2005).

Although HIV/AIDS care is a societal obligation to which many governments are committed regardless of economic considerations, nevertheless more accurate information on the societal costs of HIV/AIDS care will allow decision makers to better understand its economic impact. Given the fact that HIV prevalence rates are increasing due to falling death rates the impact of HIV on national health budgets can be expected to increase (Yazdanpanah et al., 2002; UNAIDS, 2007). The cost estimates of this paper can provide a basis for decision makers to assess the economic impact on different stages of disease and make better informed choices. Italy has the third highest prevalence of AIDS cases (after France and Spain) in Western Europe. In Italy about half (58\%) of AIDS cases are injection drug users. Italy was estimated to have around 56,076 prevalent cases of AIDS at the end of 2005 (Suligoi B et al., 2006). Prior studies on the costs of AIDS in Italy have led to the establishment of a growing research network involving over 30 AIDS clinics in North-east Italy. In 1994, and again in 1998, an Italian team conducted two separate surveys of the quality of life $(\mathrm{QoL})$ and the medical costs of these patients (Tramarin et al., 2004). Remarkable changes occurred over this four year period - increasing drug costs, decreasing hospital costs, and improved QoL. The availability of historical data as well as an existing research network renders Italy suitable for a detailed assessment of costs for HIV/AIDS.

In this study, we provide an assessment of the direct medical costs and indirect costs of HIV/AIDS care in Northern Italy. 


\section{Methods}

Study design

The study was designed as a prospective longitudinal cohort study with a time-frame of 12

Formatted: Line spacing: 1.5 lines months. A sample of patients was gathered from the infectious disease clinics of two major hospitals in Northern Italy, "Ospedale Civile di Padova" in Padua and "Ospedale L. Sacco" in Milan. Eligibility criteria included age over 18, mental competence, and agreement to be compliant with medical care and follow up. Patients were surveyed at baseline and were followed-up at 6 and 12 months. To assess the relationship between costs and stage of disease, patients were categorized into three groups at baseline depending on pre-exposure to HAART, and severity of symptoms, The category "No HAART" included HIV positive, asymptomatic

Deleted: (Table 1) patients who had CD4 counts sufficiently high so that they had never been on HAART. Patients were categorized in the second category "Stable HAART", if they had been on HAART with mild HIV infection. Mild infection was defined as having a CD4 count over

Deleted: , 200 cells/ $\mu$ l and no prior opportunistic infections. The third category "HAART failure" included patients whose primary HAART regimen had to be altered because of severe side effects or immunological failure. These patients had to meet the following criteria: (1) the patients had been on a primary HAART regimen for at least 12 weeks and had either (2a) their HAART regimen switched, stopped, or reconsidered in last 12 weeks because of immunological failure as documented by viral load and CD4 count or (2b) had major toxicity (lipodystrophy or metabolic changes) from their HAART regimen.

To enable a prospective estimate of the cost of caring for a patient for subsequent 12 months based on initial clinical stage, patients maintained their original classification throughout the study. Thus patients in "No HAART" and "Stable HAART" categories were not reclassified if their clinical stage advanced at later rounds of data collection. Subjects were then offered enrolment on a "first come first serve" basis until the enrolment quota ( 20 for each category at each clinic) for that category was reached. Informed consent from patients was gathered and the hospital ethics committees in both Milan and Padua determined that this study was exempt from human subject restrictions, as no interventions were being imposed and patients' identities were not being entered in the database. The Johns Hopkins Bloomberg School's Committee on Human Research approved the analysis of the secondary dataset and labelled this study as 'protecting human subjects'.

Cost and quality of life data

Deleted: from

Deleted: their 
We used a bottom-up analysis (Drummond MF et al., 2005) to estimate annual direct costs by counting resource use at the patient level and multiplying these with the unit prices. Resource use data was registered monthly in a cost tracking database by clinical staff. This included data on ARV drug use, (day) hospital admissions, diagnostic procedures, laboratory tests, clinic visits and consultations. Costs of drugs were calculated at $50 \%$ of the market price, representing the official drug price to the hospitals in Italy. All unit costs of medical resources are based on the National Tariff System (Minestero della Salute, 2004). Indirect costs were calculated using data collected with the "Short Form Health and Labour Questionnaire" (SFHLQ) (van Roijen et al., 1996) that was completed at baseline and at each visit. In addition, we examined rates of labour force participation and earnings as reported by the patient. Production losses were calculated assuming an average number of annual working hours in Northern Italy of 1729 with a working day of 8 hours (Eurostat, 2004). For indirect costs we included production losses due to absence from work, reduced productivity at work and reduced unpaid labour participation. Production losses due to absence from work were calculated using the human capital approach (Drummond MF et al., 2005). Production losses due to reduced productivity at work were calculated using the method proposed by Osterhaus (Osterhaus et al., 1992). Production losses due to reduced unpaid labour participation, i.e. the costs of time spent by household members or others on unpaid work that would have been performed by the patient, were estimated and valued using the average income of a household help in Northern Italy (Eurostat, 2004). All costs are reported in Euros using price levels of 2004.

At baseline and at each visit each the patient completed the AIDS Clinical Trials Group 601-2 Form which consisted of a Medical Outcomes Study HIV questionnaire as well as a visual analogue rating scale rating their current health state from 0 to 100 . This visual analogue rating was interpreted as the patient's current QoL. Additionally, a symptom tracking patient questionnaire was filled out monthly by the patient, registering the number of days per month that the patient was free of HIV symptoms or adverse drug effects.

\section{Statistical analysis}

We used a two part method to model the fact that patient cost data may contain zero costs in high frequencies in subcategories. Subsequently, parametric regression methods were used to the non-zero cost data, which tend to be not normally distributed and skewed in nature. In particular, to assess the problem of zero costs, we fitted a Generalized Linear Model, in order to determine the odds of a patient having non-zero costs, as described by Zhou et al. (Zhou X
Deleted: Resource use d

Deleted: was collected
Deleted: A

Deleted: quality of life 
et al., 2006). Subsequently, in order to estimate the expected value and the standard deviation of the non-zero and skewed cost data, we made the assumption that it follows a lognormal, generalized gamma or generalized F distribution. As described by Peng et al. (Peng et al., 1998) the generalized $F$ has the advantage of including a wide variety of distributions as special cases (such as Weibull, lognormal, log-logistic). Estimation of the distribution parameters was done with the method of maximum likelihood. The distribution that fitted best was selected using the Akaike criterion (Peng et al., 1998). The expected value and standard deviation of the non-zero costs was calculated through the moments of the distribution used (Kalbfleisch JD \& Prentice RL, 2002; Basu et al., 2004). Subsequently, these values in combination with the probability of a patient having zero costs were used to estimate the total expected value and standard deviation (Basu et al., 2004; Zhou X et al., 2006). This method produces consistent estimates of mean costs. To compare the costs by clinical category a parametric regression model was used. For the analysis of QoL, the expected value and standard deviation of the patients' QoL was calculated through the moments of a beta distribution that was fitted to the data. Subsequently, beta regression analyses were performed to investigate the determinants of the patients' QoL (Ferrari \& Cribari-Neto, 2004). The likelihood ratio test was used to select the best fitting model. The statistical analysis was carried out using Stata 9.2 (StataCorp, 2005) and R 2.5.0 (R Development Core Team, 2007).

\section{Results}

Enrolment began in January 2004 and ended May 2004. Enrolment was offered to 165 patients. A total of 121 patients agreed to enrol. The follow-up phase began 12 weeks after enrolment and continued for a subsequent period of 56 weeks. After enrolment, 2 patients were lost to follow up, leaving a sample of 119 that were surveyed at baseline. After the survey at 6 months, 6 more patients were lost to follow up, leaving a final sample for analysis of 113 patients that were surveyed at 12 months and that completed follow up. The characteristics of the sample population are shown in table $1_{i}$

\section{Direct and indirect costs}

The annual cost estimates per patient for the main cost categories are shown in table 2 together with the expected annual earnings. Parametric regression analysis showed that compared to "No HAART", "Stable HAART" and "HAART failure" had significantly higher ARV drug costs, direct costs and total costs. The significant differences in total costs were 
primarily due to the low cost of ARV drugs in the "No HAART" group (the reason there were any ARV drug costs in the No HAART group was because the categories were defined at baseline and 10 out of the 37 patients in "No HAART" were started on HAART during the follow up phase). Comparing "HAART failure" to "Stable HAART", significantly higher direct costs were found. ARV drugs contribute to direct costs but are shown as a separate category because of their large share in total costs. Included in "Direct Costs - excluding ARVs" are (day) hospital admissions, clinic visits, consultations, laboratory tests (hemochrome; CD4; viral load; panel 8; panel 20; single dose; blood-, urine-, CSF-, cryptococcal culture; toxo serology;) and procedures (Chest X-ray; tomography; CT scan; Echogram; ECG; Gastroscopy; blood transfusion; immunoglobulin- amphotericin-, erythropoietin-, daunorubicine-, chemotherapy-infusion;)

Of the distributions tested, the lognormal and generalized $\mathrm{F}$ distributions were found to describe the different cost categories best. Since the goodness of fit of these distributions on the data varied per category, the expected value of the total costs is not equal to the sum of the expected values of the individual categories.

Figure 1 shows the proportion of aggregated annual total costs of the cohort for the main cost categories, by clinical category. The contribution to the total aggregated costs of the cohort of the subcategories of direct and indirect costs are shown in table 3 ,

\section{Quality of life}

The expected value (and standard deviation) of the patients' QoL over the study period for "No HAART", "Stable HAART" and "HAART failure" was estimated at 0.80 (0.16), 0.78 $(0.17)$ and $0.64(0.20)$, respectively. ). For the beta regression analysis, we considered as baseline a patient in "No HAART", with a QoL equal to the expected value, without any household members, no paid work and experiencing symptoms all days of the month. The regression analysis showed a significant positive relation between the patients' QoL and the determinants "having paid work" $(0.25 \mathrm{p}=0.0114)$ and "monthly days without symptoms" (0.029 p=0.0158). , The patients' QoL was significantly lower in "HAART failure" compared to "No HAART" $(-0.61$ p $<0.001)$, but not significantly different between "Stable HAART" and "No HAART $\left(0.054 \mathrm{p}=0.683_{*}\right.$ Hence, compared to a baseline patient, the difference in the QoL of a patient in "HAART failure", experiencing 15 days per month without symptoms (all other variables remaining equal to baseline) would be $-16.1 \%((\exp (1 *-0.61+15 * 0.029)-1) *$ $100 \%)$.

\begin{tabular}{|c|}
\hline Deleted: 5 \\
\hline Deleted: quality of life \\
\hline $\begin{array}{l}\text { Deleted: The beta regression } \\
\text { coefficients and p-values for the } \\
\text { determinants of patients' QoL HAART } \\
\text { were }-0.61(<0.001) \text { for "HAART } \\
\text { failure", } 0.054(0.638) \text { for "Stable } \\
\text { HAART", } 0.017(0.648) \text { for "Household } \\
\text { size", } 0.25(0.0114) \text { for "Having paid } \\
\text { work" and } 0.029(0.0158) \text { for "Monthly } \\
\text { days without symptoms". }\end{array}$ \\
\hline $\begin{array}{l}\text { Deleted: determinants of patients' QoL } \\
\text { are shown in table } 6 \text {. Reference group for } \\
\text { this analysis were patients in "No } \\
\text { HAART" with QoL equal to the expected } \\
\text { value, without any household members } \\
\text { and no paid work. }\end{array}$ \\
\hline Deleted: Table 6 shows that \\
\hline Deleted: a \\
\hline Deleted: was found \\
\hline Deleted: and \\
\hline Deleted: that \\
\hline Deleted: $\mathrm{t}$ \\
\hline Deleted: and "Stable HAART" \\
\hline Deleted: \\
\hline Deleted: \\
\hline $\begin{array}{l}\text { Deleted: . The baseline patient for this } \\
\text { analysis was a patient in "No HAART", } \\
\text { with QoL equal to the expected value, } \\
\text { without any household members, no paid } \\
\text { work and experiencing symptoms all days } \\
\text { of the month. }\end{array}$ \\
\hline Deleted:". \\
\hline Deleted: E.g., \\
\hline
\end{tabular}




\section{Discussion and conclusion}

This study assesses the impact of HIV/AIDS on costs and QoL in a cohort of Italian HIV/AIDS patients. Patients were categorized by progression of disease. The total costs for patients in "No HAART" (expected value: $€ 1,818$ ) were over 6 times lower than for patients in "HAART failure" (expected value: $€ 12,332$ ), and over 5 times lower than for patients in “stable HAART” (expected value: €9,820).

Comparing "Stable HAART" to "HAART failure", we only found significantly higher direct costs. These higher direct costs are related to a higher occurrence of diagnostic procedures, consultations and laboratory tests in "HAART failure". The ARV drug costs for patients in "HAART failure" were found to be higher than for patients in "stable HAART", although this difference was not significant. A difference was expected, since the composition of therapeutic regimens of this latter category included more expensive drugs (e.g. enfuvirtide) and was associated with a more frequent use of protease inhibitors which have a higher cost than NNRTI (29\% in "stable HAART", versus $41 \%$ in "HAART failure"). Looking at the entire cohort, the costs of ARV medication made up the majority of costs, with ARV drug costs contributing $36 \%, 76 \%$ and $72 \%$ of aggregated total costs in "No HAART", "Stable HAART" and "HAART failure" respectively.

The shift in costing patterns from inpatient to outpatient care in Italy as published by a number of authors (Garattini et al., 2001; Torti et al., 2003; Tramarin et al., 2004), was confirmed by our study results, and furthermore, our results indicate that the shift has continued to the point where the contribution of inpatient care costs to the total costs for HIV/AIDS treatment have become almost negligible. During our study only 2 inpatient stays were observed in our cohort.

The indirect costs consist mainly of production losses due to absence from work and reduced productivity at work. The indirect costs are comparable in magnitude to the direct costs excluding ARVs. These high indirect costs can be explained by the relatively young population and corresponding higher labour participation of the cohort. In table 3 , when comparing the indirect costs of "Stable HAART" to "HAART failure", we see lower production losses due to absence from work combined with higher production losses due to decreased productivity at work. This result suggests that a stable HAART regimen allows a patient to come to work although at a lower productivity.

The impact of HIV/AIDS on QoL in all patient groups was clearly visible, with patients in "No HAART" (expected value: 0.80) having the highest QoL score, followed by patients in
Deleted: quality

Deleted: of life

Deleted: 5

Deleted: quality of life

Deleted: quality of life 
"stable HAART" (expected value: 0.78 ) and "HAART failure" (expected value: 0.64). The
multivariate regression analysis showed a high association between patients" QoL and having
paid work. However, the causality of this relationship remains unidentified. In this study, we used a prospective study design. The primary advantage of the prospective and longitudinal study design is that it avoids bias due to selective recall. The prospective design allowed patients to maintain symptom diaries and staff at the clinical practice to register all costs in real time. The inclusion of both a 6 month and a 12 month follow-up offered participants an opportunity to gain more experience with the study instruments. The Italian healthcare setting for HIV offers excellent data gathering opportunities, since in Italy, HIV/AIDS patients are exclusively followed up by infectious diseases specialists. All outpatient prescription drugs are dispensed in the outpatient clinic (not pharmacies) so that information on drug utilization is available from the medical record, and the same clinicians are responsible for both outpatient and inpatient care.

Levy et al. observed in a recent review on the direct costs of HIV/AIDS care a lack of comparability of studies because of different costing methods used and differences in the classification of patients. In this study, we used similar costing methodologies as Tramarin et al. (Tramarin et al., 2004), but the statistical analysis was different, making results also difficult to compare. According to this previous study, direct medical costs due to HIV/AIDS care amounted to $€ 17,250$ per person year in 1994 , and $€ 11,465$ per person year in 1998 . Our cost estimates are lower. This is due to the different methodology used to estimate the expected value, but it could also partially reflect the effects of lowered ARV drug prices and a continued shift in resource use from inpatient care to outpatient care. However, given the size of the cohort and number of study centres used in this study, the costing result may not be representative for the HIV/AIDS population in other regions of Italy.

An important finding is that despite being in treatment, many patients were still gainfully employed and generated substantial expected annual earnings ranging from $€ 14,994$ for "No HAART" patients to $€ 9,820$ for Stable HAART patients. These annual earnings exceeded the expected direct costs of their medical treatment and our analysis indicates that in this setting HIV/AIDS care enables a patient population to contribute an economic output that exceeds the expenditure on their treatment.

\section{Acknowledgement}


Authors gratefully acknowledge funding by sanofi pasteur. We are grateful to Leona van Roijen (Erasmus University Rotterdam, The Netherlands) and colleagues for permission to use the SF-HLQ instrument. We also thank the patients who generously volunteered their time to enrol in the study. 
Reference List

Basu, A., Manning, W. G., \& Mullahy, J. (2004). Comparing alternative models: log vs Cox proportional hazard? Health Econ., 13, 749-765.

Drummond MF, Sculpher MJ, Torrance GW, O'Brien BJ, \& Stoddart GL (2005). Methods for the economic evaluation of health care programmes. (Third edition ed.) Oxford: Oxford Medical Publications.

Eurostat (2004). Eurostat database.

Ferrari, S. L. P. \& Cribari-Neto, F. (2004). Beta regression for modelling rates and proportions. Journal of Applied Statistics, 31, 799-815.

Garattini, L., Tediosi, F., Di Cintio, E., Yin, D., \& Parazzini, F. (2001). Resource utilization and hospital cost of HIV/AIDS care in Italy in the era of highly active antiretroviral therapy. AIDS Care, 13, 733-741.

Gebo, K. A., Chaisson, R. E., Folkemer, J. G., Bartlett, J. G., \& Moore, R. D. (1999). Costs of HIV medical care in the era of highly active antiretroviral therapy. AIDS, 13, 963969.

Kalbfleisch JD \& Prentice RL (2002). The Statistical Analysis of Failure Time Data. (second edition ed.) Wiley.

Levy, A. R., James, D., Johnston, K. M., Hogg, R. S., Harrigan, P. R., Harrigan, B. P. et al. (2006). The direct costs of HIV/AIDS care. Lancet Infect.Dis., 6, 171-177. 
Minestero della Salute (2004). Tariffario regionale anno 2004 per la remunerazione delle prestazione di assistenza ospedaliera (Rep. No. DGRV 889/04).

Mocroft, A., Monforte, A., Kirk, O., Johnson, M. A., Friis-Moller, N., Banhegyi, D. et al. (2004). Changes in hospital admissions across Europe: 1995-2003. Results from the EuroSIDA study. HIV.Med., 5, 437-447.

Mocroft, A., Vella, S., Benfield, T. L., Chiesi, A., Miller, V., Gargalianos, P. et al. (1998). Changing patterns of mortality across Europe in patients infected with HIV-1. EuroSIDA Study Group. Lancet, 352, 1725-1730.

Osterhaus, J. T., Gutterman, D. L., \& Plachetka, J. R. (1992). Healthcare resource and lost labour costs of migraine headache in the US. Pharmacoeconomics., 2, 67-76.

Palella, F. J., Jr., Delaney, K. M., Moorman, A. C., Loveless, M. O., Fuhrer, J., Satten, G. A. et al. (1998). Declining morbidity and mortality among patients with advanced human immunodeficiency virus infection. HIV Outpatient Study Investigators. N.Engl.J.Med., 338, $853-860$.

Peng, Y., Dear, K. B., \& Denham, J. W. (1998). A generalized F mixture model for cure rate estimation. Stat.Med., 17, 813-830.

R Development Core Team (2007). A Language and Environment for Statistical Computing. (Version 2.5.0) [Computer software]. Vienna, Austria: R Foundation for Statistical Computing.

StataCorp (2005). Stata Statistical Software (Version 9.2) [Computer software]. College Station, TX: StataCorp LP. 
Suligoi B, Boros S, Camoni L, Lepore D, Ferri M, \& Roazzi P (2006). Aggiornamento dei casi di AIDS notificati in Italia al 31 Dicembre 2005. Notiziario Istituto Sanità 2006, 19 supp 1, 1-24.

Torti, C., Casari, S., Palvarini, L., Quiros-Roldan, E., Moretti, F., Leone, L. et al. (2003). Modifications of health resource-use in Italy after the introduction of highly active antiretroviral therapy (HAART) for human immunodeficiency virus (HIV) infection. Pharmaco-economic implications in a population-based setting. Health Policy, 65, 261-267.

Tramarin, A., Postma, J., Gerzeli, S., Campostrini, S., \& Starace, F. (2004). The clinical and economic efficacy of HAART: a shift from inpatient medical to outpatient pharmaceutical care for HIV/AIDS patients in Northeastern Italy. AIDS Care, 16, 213-218.

UNAIDS (2007). UNAIDS Report on the global AIDS epidemic.

van Roijen, L., Essink-Bot, M. L., Koopmanschap, M. A., Bonsel, G., \& Rutten, F. F. (1996). Labor and health status in economic evaluation of health care. The Health and Labor Questionnaire. Int.J.Technol.Assess.Health Care, 12, 405-415.

Yazdanpanah, Y., Goldie, S. J., Losina, E., Weinstein, M. C., Lebrun, T., Paltiel, A. D. et al. (2002). Lifetime cost of HIV care in France during the era of highly active antiretroviral therapy. Antivir.Ther., 7, 257-266.

Zhou X, Qin G, \& Maciejewski M (2006). Estimating the VA total health care cost using a semi-parametric heteroscedastic two-part model. Services and Outcomes Research Methodology, 6, 69-80. 
Tables and figure

\begin{tabular}{|c|c|c|c|c|c|}
\hline \multirow{2}{*}{\multicolumn{5}{|c|}{ 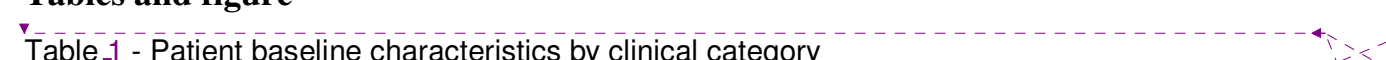 }} & \multirow{4}{*}{$\begin{array}{l}\text { Deleted: } 3 \\
\text { Deleted: II } \\
\text { Table } 1 \text { - Categorization of patients } \\
\text { according to severity of HIV infection.II } \\
\text { II }\end{array}$} \\
\hline & & & & & \\
\hline & No HAART & Stable HAART & HAART failure & Total & \\
\hline $\mathrm{N}(\%)$ & $37(31.1 \%)$ & $42(35.3 \%)$ & $40(33.6 \%)$ & $119(100.0 \%)$ & \\
\hline Male N (\%) & $22(59.5 \%)$ & $28(66.7 \%)$ & $28(70.0 \%)$ & $78(65.5 \%)$ & \multirow{10}{*}{$\begin{array}{l}\text { Formatted: Comment Text, Left, } \\
\text { Indent: Left: } 0 \text { pt }\end{array}$} \\
\hline Age mean (SD) & $37.0(7.0)$ & $40.4(9.4)$ & $41.1(7.4)$ & $39.6(8.1)$ & \\
\hline CD4 mean (SD) & $583.2(348.4)$ & $544.2(305.7)$ & 330.7(229.8) & $484.6(315.1)$ & \\
\hline $\begin{array}{l}\text { Viral load mean } \\
\text { (range) }\end{array}$ & $\begin{array}{l}49,069(U- \\
260,392)\end{array}$ & 1,683 (U-48,200) & $\begin{array}{l}39,290(\mathrm{U}- \\
510,000)\end{array}$ & $\begin{array}{l}29,373(U- \\
510,000)\end{array}$ & \\
\hline Bisexual (\%) & $2(5.4 \%)$ & $3(7.1 \%)$ & $3(7.3 \%)$ & $8(6.7 \%)$ & \\
\hline Heterosexual (\%) & 15 (40.5\%) & $21(50.1 \%)$ & $13(31.7 \%)$ & 49 (41.2\%) & \\
\hline Drug User (\%) & $4(10.8 \%)$ & $8(19.0 \%)$ & $17(41.5 \%)$ & $29(23.5 \%)$ & \\
\hline Homosexual (\%) & $16(43.3 \%)$ & $9(21.4 \%)$ & $7(17.1 \%)$ & $32(26.9 \%)$ & \\
\hline Unknown $(\%)$ & $0(0.0 \%)$ & $1(2.4 \%)$ & $1(2.4 \%)$ & $2(1.7 \%)$ & \\
\hline Having paid work & $31(83.8 \%)$ & $28(66.7 \%)$ & $22(55.0 \%)$ & $81(68.1 \%)$ & \\
\hline
\end{tabular}

HAART highly active antiretroviral therapy; SD standard deviation; U Undetectable; 
Table 2 - Expected values (with standard deviation) of annual costs of ARV drugs, direct costs excluding ARVs, indirect costs and total costs, as well as the expected value of the annual earnings (including patients without paid work), as derived from the fitted distribution, per patient by clinical category, in Euros (price levels of 2004). Also shown are p-values of the tests for significant difference among groups.

\begin{tabular}{|c|c|c|c|c|c|c|}
\hline & \multirow{2}{*}{$\begin{array}{r}\text { No HAART (1) } \\
\text { EV (SD) }\end{array}$} & \multicolumn{2}{|c|}{ Stable HAART (2) } & \multicolumn{3}{|c|}{ HAART failure (3) } \\
\hline & & EV (SD) & p (2 vs 1) & EV (SD) & p (3 vs 1) & p (3 vs 2) \\
\hline Direct - ARV drugs 1 & $1,045(681)$ & $6,208(4,049)$ & 0.0187 & $7,066(4,608)$ & 0.00327 & 0.264 \\
\hline Direct - ex ARVs ${ }^{1}$ & 871 (895) & $1,129(1,160)$ & 0.0104 & $1,457(1,497)$ & $<0.001$ & 0.0158 \\
\hline Indirect $^{1}$ & $1,155(1,945)$ & $695(1,170)$ & 0.196 & $1,751(2,949)$ & 0.983 & 0.144 \\
\hline Total costs ${ }^{2}$ & $1,818(1,502)$ & $9,075(7,494)$ & $<0.001$ & $12,332(10,183)$ & $<0.001$ & 0.0626 \\
\hline Earnings $^{2}$ & $14,994(5,535)$ & $10,811(3,991)$ & 0.723 & $9,820(3,625)$ & 0.953 & 0.749 \\
\hline
\end{tabular}

${ }^{1}$ Fitted with a lognormal distribution

${ }^{2}$ Fitted with a generalized F distribution

EV expected value; SD standard deviation; ARV antiretroviral; HAART highly active antiretroviral therapy 
Deleted: 5
Table 3 - Total aggregated direct costs of the cohort by clinical category, subdivided by antiretroviral drugs, laboratory tests, procedures, consultations and inpatient care. Also shown are total aggregated indirect costs of the cohort by clinical category, subdivided by production losses due to absence from work, production losses due to reduced

productivity at work and costs due to reduced unpaid labour participation.

\begin{tabular}{lrrr}
\hline Clinical category & No HAART & Stable HAART & HAART failure \\
\hline Direct costs & $\mathbf{6 2 , 4 1 0}(\mathbf{1 0 0 \%})$ & $\mathbf{2 8 0 , 3 9 6}(\mathbf{1 0 0 \%})$ & $\mathbf{3 3 8 , 6 3 8}(\mathbf{1 0 0 \%})$ \\
ARV drugs & $33,387(53 \%)$ & $238,391(85 \%)$ & $281,259(83 \%)$ \\
Laboratory tests & $26,210(42 \%)$ & $36,858(13 \%)$ & $42,165(12 \%)$ \\
Procedures & $524(1 \%)$ & $1,596(1 \%)$ & $5,340(2 \%)$ \\
Consultations & $2,288(4 \%)$ & $3,550(1 \%)$ & $4,183(1 \%)$ \\
Inpatient care & $0(0 \%)$ & $0(0 \%)$ & $5,690(2 \%)$ \\
Indirect costs & $\mathbf{3 0 , 9 4 0 ( 1 0 0 \% )}$ & $\mathbf{3 2 , 5 4 6}(\mathbf{1 0 0 \%})$ & $\mathbf{5 1 , 6 1 2}(\mathbf{1 0 0 \%})$ \\
Absence & $24,442(79 \%)$ & $16,500(51 \%)$ & $41,441(80 \%)$ \\
Reduced productivity & $5,165(17 \%)$ & $13,885(43 \%)$ & $7,506(15 \%)$ \\
Unpaid labour & $1,333(4 \%)$ & $2,161(6 \%)$ & $2,666(5 \%)$ \\
\hline
\end{tabular}

ARV antiretroviral; HAART highly active antiretroviral therapy

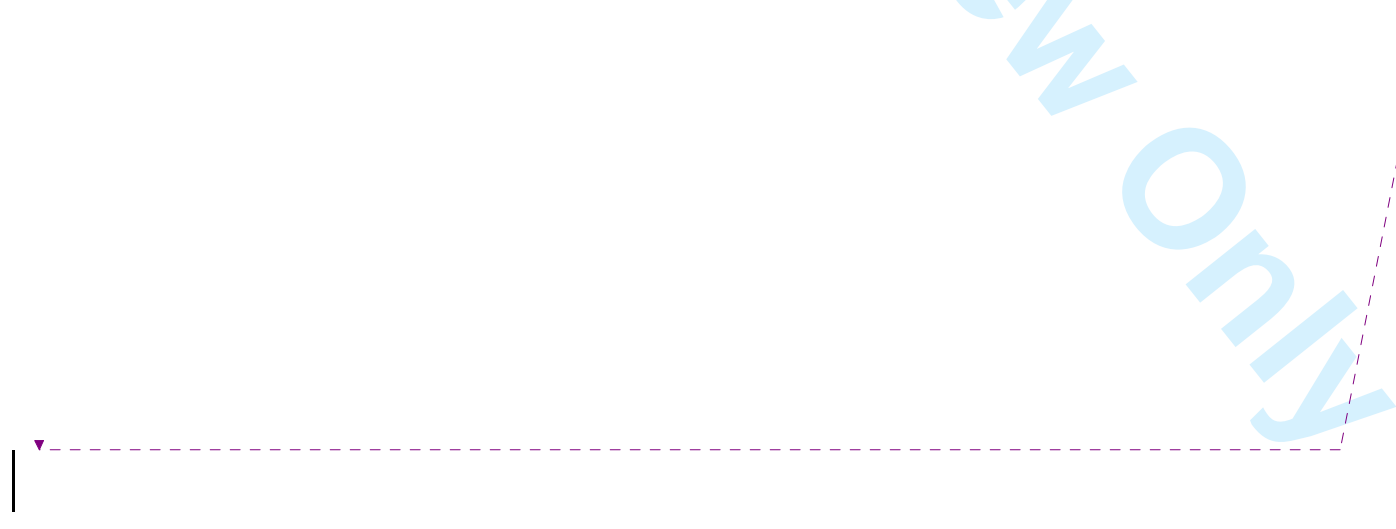




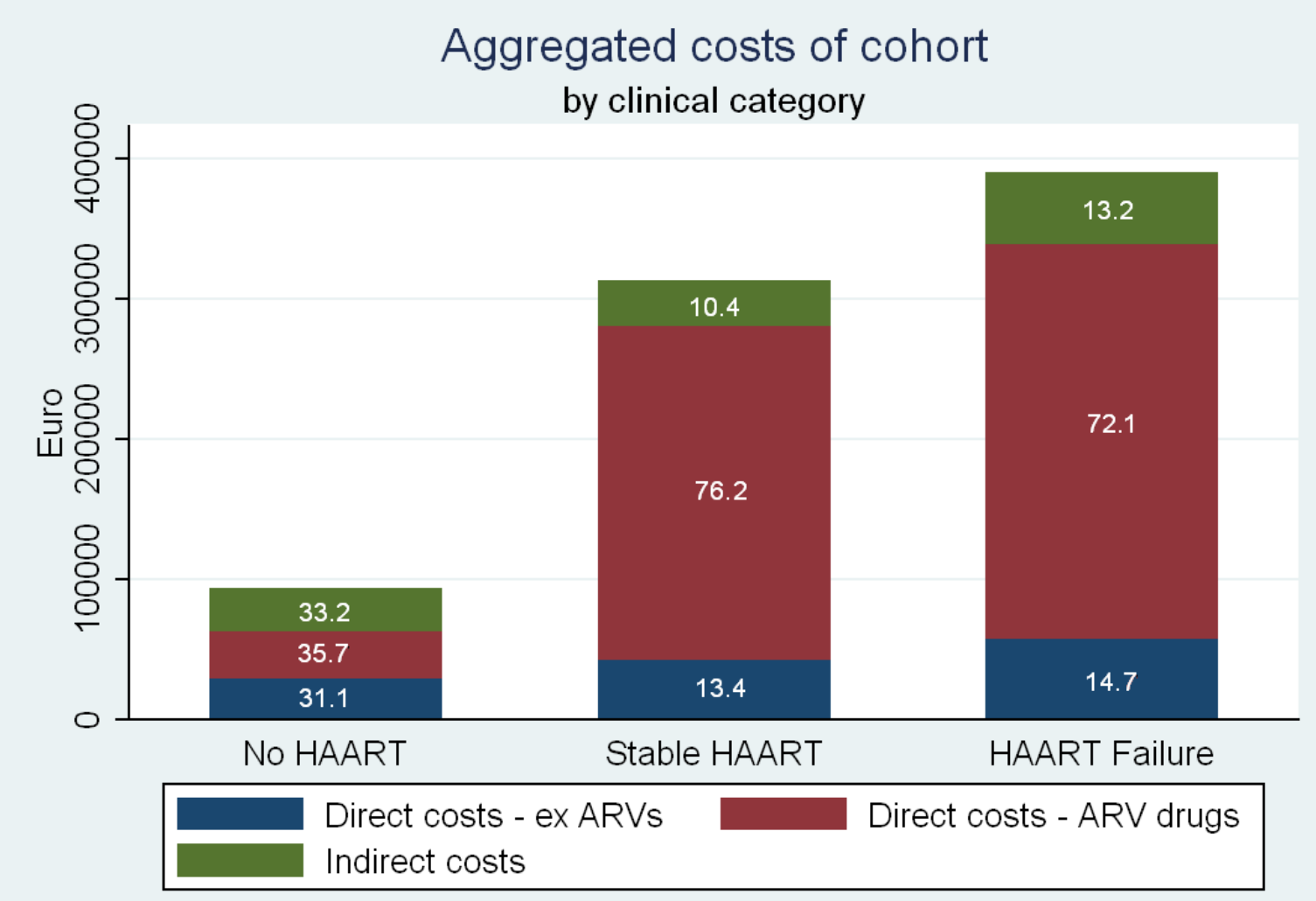

Figure 1 - Total aggregated costs of the cohort by clinical category, subdivided by antiretroviral drug costs, direct cost excluding antiretroviral drugs and indirect costs. Also shown are the percentages of the total costs in each the clinical category.

ARV antiretroviral; HAART highly active antiretroviral therapy 
Table 1 - Categorization of patients according to severity of HIV infection.

\begin{tabular}{ll}
\hline No HAART & $\begin{array}{l}\text { HIV positive, asymptomatic patients who have CD4 counts sufficiently } \\
\text { high so that they have never been on HAART. }\end{array}$ \\
\hline Stable HAART & $\begin{array}{l}\text { Patients on HAART with mild HIV infection defined as having a CD4 } \\
\text { count over 200 cells/ } \mu \text { l and no prior opportunistic infections. }\end{array}$ \\
\hline HAART & Patients whose primary HAART regimen had to be altered because of \\
failure & $\begin{array}{l}\text { severe side effects or immunological failure. These patients had to meet } \\
\text { the following criteria: } 1 \text { ) Had been on a primary HAART regimen for at }\end{array}$ \\
& $\begin{array}{l}\text { least } 12 \text { weeks and had either 2a) their HAART regimen switched, } \\
\text { stopped, or reconsidered in last } 12 \text { weeks because of immunological } \\
\text { failure as documented by viral load and CD4 count or 2b) had major } \\
\text { toxicity (lipodystrophy or metabolic changes) from their HAART } \\
\text { regimen. }\end{array}$
\end{tabular}

HAART highly active antiretroviral therapy

Page Break

Table 2 - Overview and description of measurement instruments used and the time(s) of measurement.

\begin{tabular}{lll}
\hline Study Instrument & Description & Time of measurement \\
\hline $\begin{array}{l}\text { Baseline patient } \\
\text { questionnaire }\end{array}$ & Age, gender, ethnicity, & Baseline \\
$\begin{array}{l}\text { Direct Cost Tracking } \\
\text { Electronic Database }\end{array}$ & $\begin{array}{l}\text { Resource use of antiretroviral drugs, } \\
\text { outpatient- and inpatient care. }\end{array}$ & $\begin{array}{l}\text { Updated monthly for each } \\
\text { patient by clinical staff, } \\
\text { during a period of 12 months } \\
\text { from time of inclusion }\end{array}$ \\
& & \\
$\begin{array}{l}\text { Short form health and } \\
\text { labour questionnaire (van } \\
\text { Roijen et al., 1996) }\end{array}$ & $\begin{array}{l}\text { Production losses due to patient's } \\
\text { disability consisting of production } \\
\text { losses due to absence from work, } \\
\text { reduced productivity at work and } \\
\text { reduced unpaid labour participation. }\end{array}$ & $\begin{array}{l}\text { Baseline } \\
6 \text { months } \\
12 \text { months }\end{array}$ \\
& & \\
\hline
\end{tabular}




\begin{tabular}{lll}
\hline $\begin{array}{l}\text { Medical Outcomes Study } \\
\text { HIV questionnaire }\end{array}$ & $\begin{array}{l}\text { Quality of life of patient measured by } \\
\text { visual analogue scale }\end{array}$ & $\begin{array}{l}\text { Baseline } \\
6 \text { months } \\
12 \text { months }\end{array}$ \\
$\begin{array}{l}\text { Symptom patient } \\
\text { questionnaire }\end{array}$ & $\begin{array}{l}\text { The number of days per month that the } \\
\text { patient was free of HIV symptoms or } \\
\text { adverse drug effects. }\end{array}$ & $\begin{array}{l}\text { Filled out monthly by patient } \\
\text { for a period of } 12 \text { months } \\
\text { from time of inclusion. }\end{array}$
\end{tabular}

Page Break

Table 6 - Beta regression coefficients and p-values of the determinants of the patients' quality of life. The baseline for this analysis is a "No HAART" patient with a QoL equal to the expected value, without household members, no paid work and experiencing symptoms all days of the months. E.g., compared to a baseline patient, the difference in the QoL of a patient in "HAART failure", experiencing 15 days per month without symptoms (all other variables remaining equal to baseline) would be $-16.1 \%$ ( $\exp \left(1 *_{-}\right.$ $0.61+15 * 0.029)-1) * 100 \%)$.

\begin{tabular}{lrr}
\hline $\begin{array}{l}\text { Explanatory } \\
\text { variable }\end{array}$ & Patients' QoL & \multicolumn{1}{l}{ P } \\
\hline HAART failure & -0.61 & $<0.001$ \\
Stable HAART & 0.054 & 0.638 \\
Household size & 0.017 & 0.648 \\
Having paid work & 0.25 & 0.0114 \\
Monthly days & 0.029 & 0.0158 \\
without symptoms & & \\
\hline
\end{tabular}

ARV antiretroviral; HAART highly active antiretroviral therapy; QoL quality of life 